\title{
Effects of Major Components of Synovial Fluid on the Morphology and Wear Rate of Polyetheretherketone (PEEK) Particles under an Accelerated Wear Process
}

\author{
Chen-Ying Su ${ }^{1}$, Shih-Shuan Huang ${ }^{1}$ and Hsu-Wei Fang ${ }^{1,2, *}$ \\ 1 Department of Chemical Engineering and Biotechnology, National Taipei University of Technology, 1, Sec. 3, \\ Zhongxiao E. Rd., Taipei 10608, Taiwan; chenying.su@ntut.edu.tw (C.-Y.S.); felaien@yahoo.com.tw (S.-S.H.) \\ 2 Institute of Biomedical Engineering and Nanomedicine, National Health Research Institutes, \\ No. 35, Keyan Road, Zhunan Town, Miaoli County 35053, Taiwan \\ * Correspondence: hwfang@ntut.edu.tw
}

Received: 2 May 2018; Accepted: 6 June 2018; Published: 8 June 2018

\begin{abstract}
Wear particle-induced biological responses are the major factors for the failure of total joint arthroplasties, but it is possible to improve the lubrication and reduce the wear of an artificial joint system. Polyetheretherketone (PEEK), with ultra-high molecular weight polyethylene, is a suitable bearing material due to its resistance to fatigue strain. However, the effects of major compositions of synovial fluid on the wear of PEEK are unclear. We characterized the effects of three major components of synovial fluid including albumin, globulin, and phospholipids on the morphology and wear rate of PEEK wear particles. Our results demonstrated that the concentrations of albumin and globulin could affect the morphology of PEEK wear particles. In addition, a higher concentration of globulin and phospholipids $(12.5 \mathrm{mg} / \mathrm{mL})$ resulted in an increase in the amount of wear particles by 2.8 - and 1.7-fold, respectively. In contrast, increasing albumin caused a reduction of wear particle numbers. These results indicate increasing concentration of albumin or reducing concentration of globulin or phospholipids has a better effect on reducing the numbers of wear particles and provides a potential solution of reducing PEEK wear particles, thus it can be more effectively applied in other biomedical systems.
\end{abstract}

Keywords: polymer; bio-tribology; joint prostheses

\section{Introduction}

The performance of total joint arthroplasties (TJAs) is mainly determined by their tribological properties because the wear particles that are generated from the tribological process play a key role in the lifetime of artificial joint system [1-3]. In addition, wear particles may further induce biological responses from surrounding tissues and cells [4-7]. The main material for artificial joints is an ultra-high molecular weight polyethylene (UHMWPE), which has been proven to function well and is widely used clinically. However, it has been shown that the wear of UHMWPE and wear particles induced osteolysis and bone resorption [8-10]. The average life time of UHMWPE is around 10 years, and patients may have to undergo surgery again for joint replacement. Therefore, researchers have been looking for better bearing materials for TJA. Another polymeric material, polyetheretherketone (PEEK), has been introduced as bearing materials for TJAs due to its resistance to fatigue strain, and has been widely used for spinal instrumentation [11,12]. Therefore, PEEK has been considered as an alternative material for TJA device.

Many studies have shown that the size of wear particles is critical for particle-induced biological responses [13-18]. It has been demonstrated in vitro that UHMWPE wear particles with a mean size of 0.24 to $7.2 \mu \mathrm{m}$ are more proinflammatory $[13,14,16,17]$, while PEEK wear particles only induce 
cytotoxicity at a size larger than $10 \mu \mathrm{m}$ [19]. Many factors can affect the sizes of wear particles, including the materials of contact surfaces and sliding conditions [20,21]. Human synovial fluid is mainly composed with albumin, globulin, lipid, and hyaluronic acid (HA), and these components may also contribute to determining the sizes of generated wear particles. Our previous study [22] has set up an accelerated wear testing protocol by sliding PEEK with microfabricated surfaces in a linear motion to generate large amounts of PEEK wear particles. Although the motion of artificial joints is rotational and linear, only the linear motion was investigated in this study.

We investigated PEEK wear characteristics under the lubrication of three major components of synovial fluid in this study. A combined analysis of the wear particle morphology and numbers of PEEK wear particles during an accelerated wear process could help us to understand the lubricating effects of synovial fluid on the characteristics of wear particles. Our results may provide feasibility for developing lubricating additives to reduce the PEEK wear particle-induced biological responses in TJAs.

\section{Material and Methods}

\subsection{Materials}

PEEK cylinder pins were obtained from A-SPINE Asia Co. Ltd. (Taiwan, Taibei) (batch number was SSR 0151). The pins were $6.35 \mathrm{~mm}$ in diameter and $25.4 \mathrm{~mm}$ in length with diamond turning on both end surfaces without polishing. Human serum albumin (HSA, Sigma-Aldrich A9511), (St. Louis, MO, USA) human immunoglobulin G (IgG, Sigma-Aldrich I4506), (St. Louis, MO, USA) and dipalmitoyl phosphatidyl choline (DPPC, Sigma-Aldrich P1652) (St. Louis, MO, USA) powders tested in this study were prepared in phosphate buffered saline (PBS, UniRegion UR-PBS001), (New Taipei City, Taiwan) with four different concentrations $(0.1 \mathrm{mg} / \mathrm{mL}, 0.5 \mathrm{mg} / \mathrm{mL}, 2.5 \mathrm{mg} / \mathrm{mL}$, and $12.5 \mathrm{mg} / \mathrm{mL})$. Because PEEK is hydroscopic, all PEEK pins were presoaked in PBS for at least 30 days at $25^{\circ} \mathrm{C}$ so they would not absorb HSA, IgG, or DPPC during the tests. Thus, the consistency of tests could be maintained.

\subsection{Wear Process}

By rubbing PEEK pin with the cutting edges of the silicon surface textures, the PEEK wear particles were generated. ASTM F732 was used as a guideline. The setup of the system was described and shown in Figure 1a [23]. Before testing, the PEEK pin was weighed three times and the average was obtained. Linear reciprocating wear tests were performed at $25^{\circ} \mathrm{C}$ under a nominal contact pressure of $1.5 \mathrm{MPa}$, a stroke length of $19 \mathrm{~mm}$, and an average sliding speed of $57.2 \mathrm{~mm} / \mathrm{s}$ in $5 \mathrm{~mL}$ of each lubricant for 6 hours (Figure 1b). After wear process, the PEEK pin was weighed three times and the average was obtained. Then the averaged weight of PEEK pin before the wear process was subtracted by the averaged weight after the process to obtain the weight loss. Wear rate was obtained when the weight loss (mg) of PEEK pin was divided by $360 \mathrm{~min}$. Four pins were tested for each lubricant. 
(a)

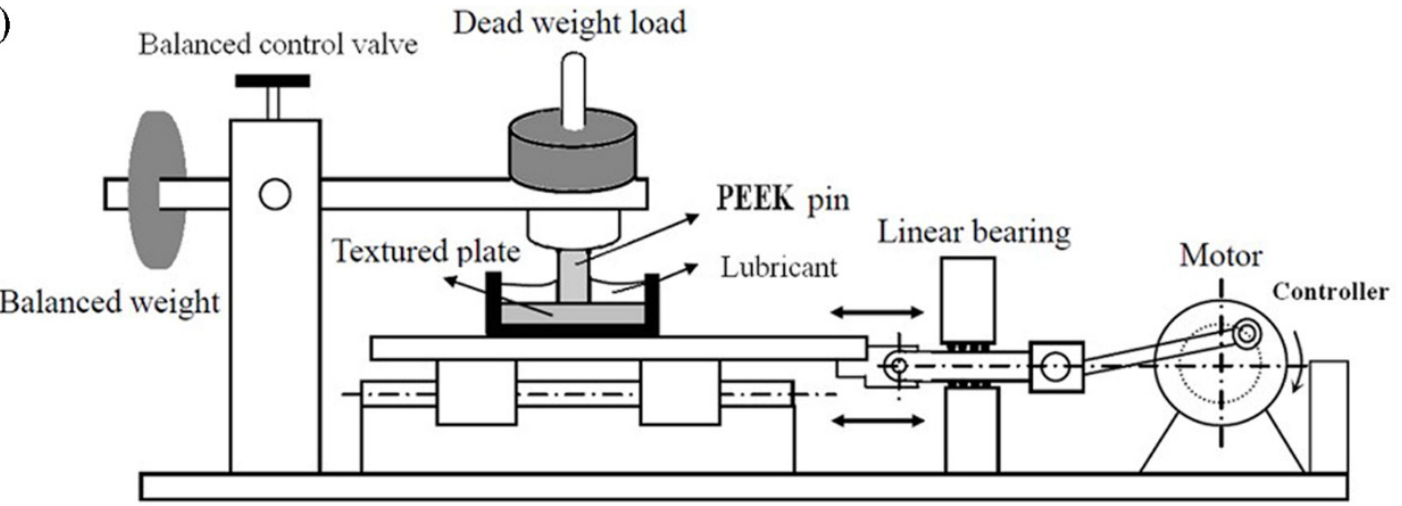

(b)

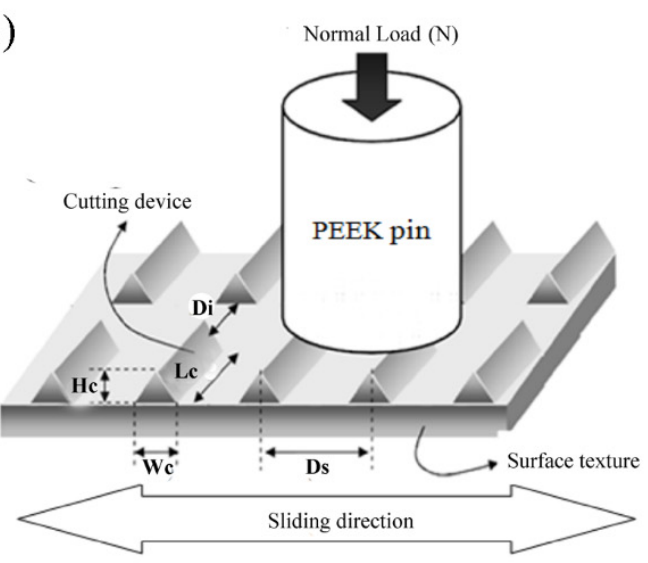

(c)
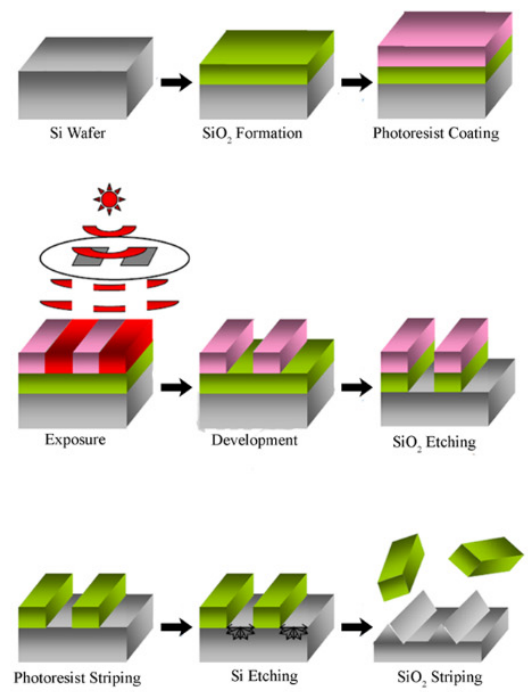

(d)
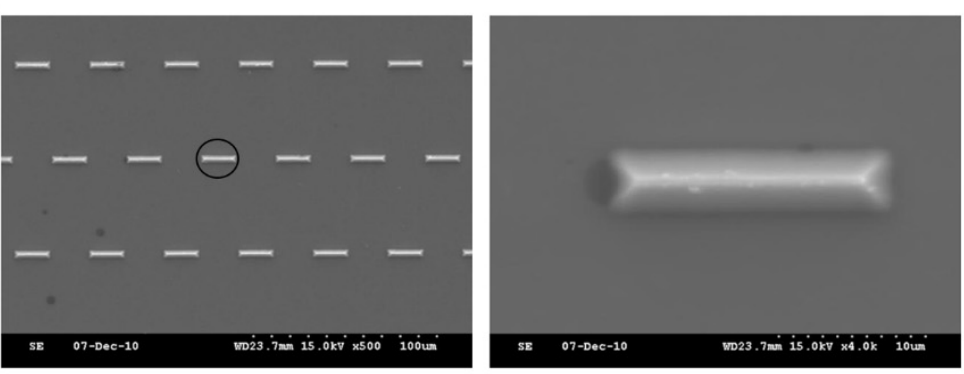

Figure 1. SEM images of the microfabricated surfaces. (a) Schematic of the setup for linear reciprocating wear testing. (b) Schematic of the particle generation in which microfabricated surface texture is rubbed against PEEK pin. Di: distance between adjacent features. Ds: pitch in the sliding direction. Lc: cutting-edge length. Wc: cutting-edge width. Hc: cutting-edge height. (c) Illustration of microfabricated surface textures process. (d) The wedges used in this study are $5 \mu \mathrm{m}$ in width and $20 \mu \mathrm{m}$ in length. The texture in the black circle is magnified on the right.

\subsection{Microfabricated Surface Textures}

The silicon wafer surface with controlled asperities was prepared by photolithography patterning and etching of the bulk substrate as previously described [24] and shown in Figure 1c. Once the surface textures were made, a layer of a 5-nm Chromium was coated onto the surface. In this study, the dimensions of the surface textures were measured from scanning electron microscopy (SEM) observations and the features were $5 \mu \mathrm{m}$ in width and $20 \mu \mathrm{m}$ in length (Figure $1 \mathrm{~d}$ ). 


\subsection{Isolation of the Wear Particles}

PEEK particles were collected by repeated water rinsing of the sample in a sample holder, and parts that came into contact with particles were moved into a sterilized beaker. The process of isolation was previously described in detail [22].

\subsection{Analysis of the Particles}

After wear particles were isolated, they were examined by using a scanning electron microscope (SEM). Micrographs of the particles were then analyzed by using an image analyzer software (Scion Image, a personal computer version of NIH Image) to measure their dimensions. Measurements were made for at least 300 particles in each condition.

\section{Results and Discussion}

\subsection{The Morphology of Wear Particles Depends on the Concentration of HSA and IgG but Not DPPC}

Table 1 listed the length, width, aspect ratio of the PEEK wear particles, as well as mass wear and wear rate under the lubrication of HSA, IgG, and DPPC, respectively. The SEM images of the wear particles under the lubrication of HSA, IgG, and DPPC were shown in Figure 2. Aspect ratio was obtained by dividing the length into the width of wear particles, and an increase in aspect ratio was associated with rod-like shape while the decrease in aspect ratio indicated granular shape. When PEEK pin was articulated in HSA solution, increasing the concentration of HSA resulted in an increase in the length and aspect ratio (Figures $2 \mathrm{a}$ and 3). When PEEK pin was rubbed in IgG solution, both particle length and width were increased but aspect ratio was decreased suggesting that increased IgG concentration was associated with generating granular shape wear particle (Figures $2 b$ and 3 ). The morphology of wear particles was not changed dramatically when PEEK pin was rubbed in DPPC solution, suggesting that the sizes of wear particles were not affected by the concentration of DPPC (Figure 2c).

Table 1. Morphology and wear of PEEK particles in different components of synovial fluid.

\begin{tabular}{ccccccc}
\hline Component & $\begin{array}{c}\text { Concentration } \\
(\mathbf{m g} / \mathbf{m L})\end{array}$ & $\begin{array}{c}\text { Particle } \\
\text { length }(\boldsymbol{\mu m})\end{array}$ & $\begin{array}{c}\text { Particle } \\
\text { width }(\boldsymbol{\mu m})\end{array}$ & Aspect ratio & $\begin{array}{c}\text { Mass wear } \\
(\mathbf{m g})\end{array}$ & $\begin{array}{c}\text { Wear rate } \\
(\mathbf{m g} / \mathbf{m i n})\end{array}$ \\
\hline \multirow{3}{*}{ HSA } & 0.1 & $4.33 \pm 3.31$ & $2.14 \pm 1.51$ & $2.08 \pm 1.03$ & 48.8 & 0.136 \\
& 0.5 & $3.47 \pm 2.63$ & $1.41 \pm 0.85$ & $2.56 \pm 1.27$ & 14.7 & 0.041 \\
& 2.5 & $4.90 \pm 3.70$ & $1.96 \pm 1.23$ & $2.54 \pm 1.26$ & 28.0 & 0.078 \\
IgG & 12.5 & $10.52 \pm 7.01$ & $2.96 \pm 1.08$ & $3.60 \pm 2.16$ & 22.9 & 0.064 \\
\hline & 0.1 & $5.77 \pm 3.17$ & $2.12 \pm 0.97$ & $2.72 \pm 1.55$ & 5.8 & 0.016 \\
& 0.5 & $6.11 \pm 3.24$ & $2.39 \pm 1.07$ & $2.77 \pm 1.60$ & 15.6 & 0.043 \\
DPPC & 2.5 & $4.91 \pm 4.07$ & $2.08 \pm 1.28$ & $2.32 \pm 1.15$ & 13.8 & 0.038 \\
& 12.5 & $7.75 \pm 3.55$ & $3.80 \pm 1.54$ & $2.17 \pm 0.87$ & 14.7 & 0.041 \\
\hline & 0.1 & $4.21 \pm 2.65$ & $1.97 \pm 1.01$ & $2.16 \pm 0.86$ & 16.3 & 0.045 \\
& 0.5 & $4.28 \pm 2.81$ & $2.19 \pm 1.32$ & $2.05 \pm 0.81$ & 20.9 & 0.058 \\
\end{tabular}


(a) HSA
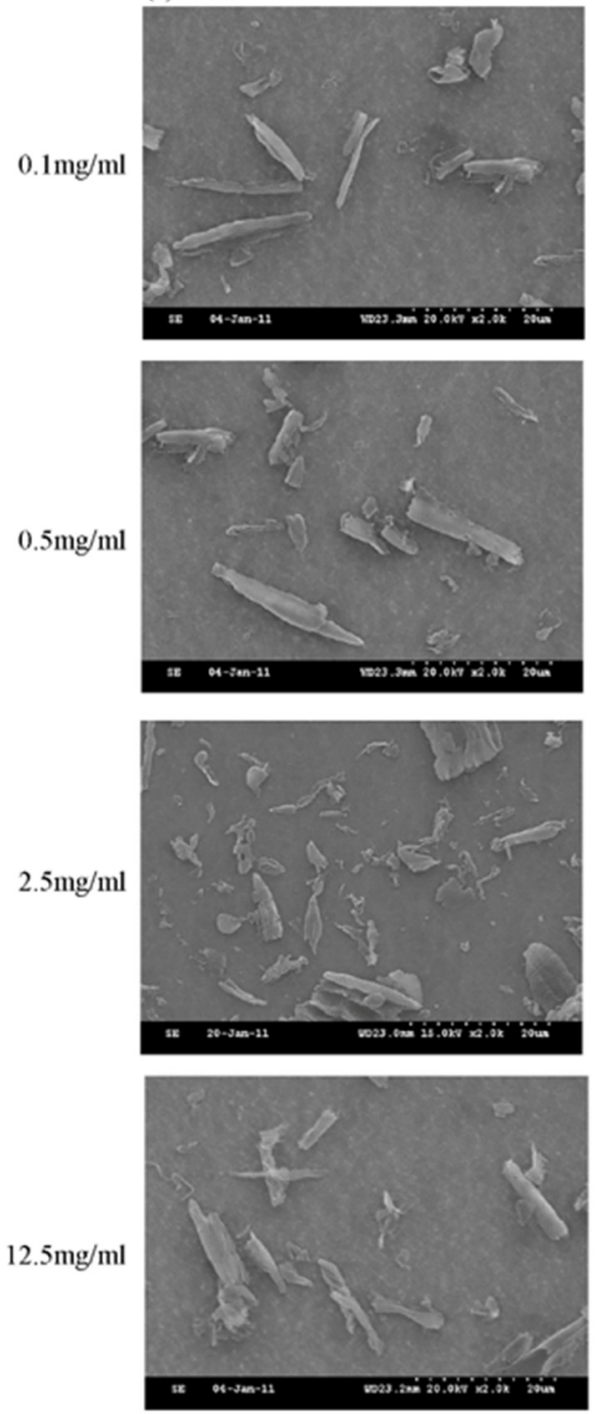

(b) $\mathrm{IgG}$
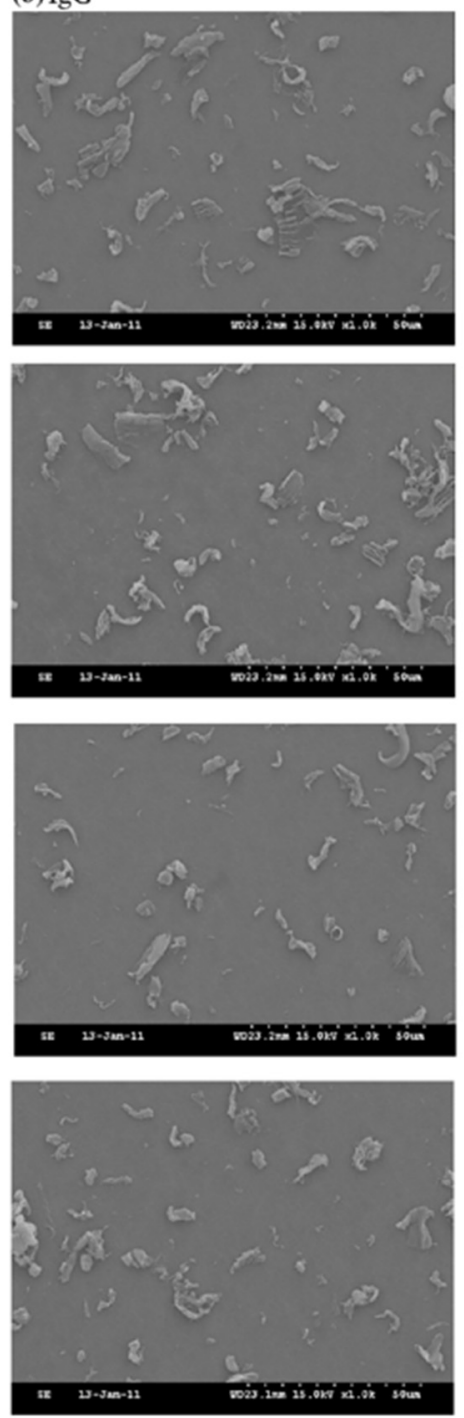

(c) DPPC
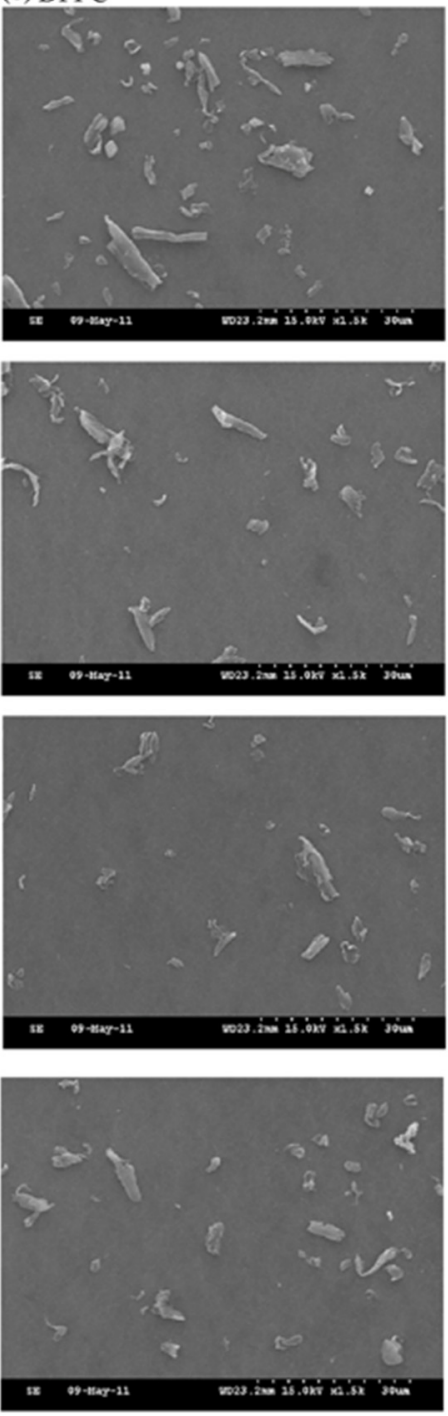

Figure 2. Morphology of PEEK wear particles under the lubrication of HSA, IgG or DPPC solution. (a) SEM images of the PEEK wear particles caused by rubbing PEEK pin against microfabricated surfaces in $0.1,0.5,2.5$, and $12.5 \mathrm{mg} / \mathrm{mL}$ HSA solution (2000 $\times$ magnification). (b) SEM images of the PEEK wear particles caused by rubbing PEEK pin against microfabricated surfaces in $0.1,0.5,2.5$, and $12.5 \mathrm{mg} / \mathrm{mL}$ IgG solution (1000 × magnification). (c) SEM images of the PEEK wear particles caused by rubbing PEEK pin against microfabricated surfaces in $0.1,0.5,2.5$, and $12.5 \mathrm{mg} / \mathrm{mL}$ DPPC solution (1500× magnification).

Our results demonstrated that increasing concentration of DPPC had no effect on the aspect ratio of PEEK wear particles. The changes in aspect ratio of particles were opposite when rubbing PEEK in HSA and IgG: a higher concentration of HSA resulted in a rod-like shape of particles while a higher concentration of IgG caused a granular shape of particles (Figure 2a,b). It has been shown that when polymers were absorbed in water, various effects could occur including a reduction in strength, a decrease in modulus of elasticity, an increase in the elongation to break, or swelling of the surface layers resulting in differential expansion $[25,26]$. 


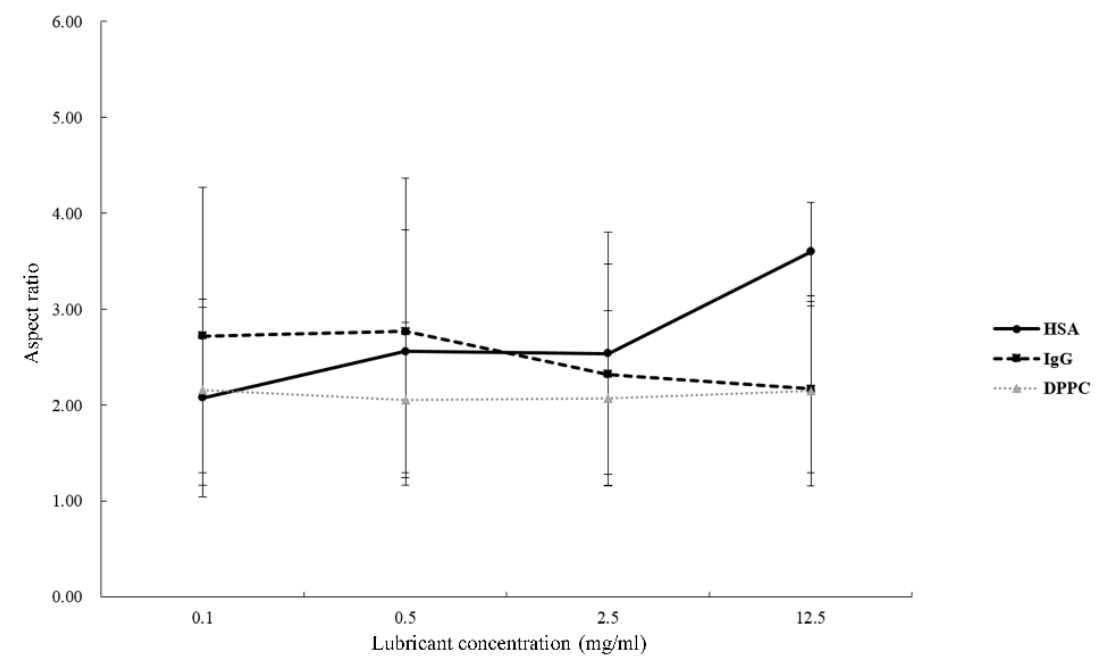

Figure 3. Aspect ratio of PEEK wear particles under the lubrication of HSA, IgG or DPPC solution. Plots of aspect ratio and the wear rate in different concentrations of HSA, IgG or DPPC solution.

The wear process of the surface feature over PEEK results in a resisting force $F_{r}$ on PEEK (Figure 4). The vertical direction of this resisting force $\mathrm{F}_{\mathrm{rz}}$ pushes up the PEEK while lateral movement continues. The interfacial friction $\left(\mathrm{F}_{\mathrm{f}}\right)$ is manifested as an encounter force to prevent the PEEK being pushed away. If the component causes an increase of interfacial friction, it will lead to a larger downward force $\mathrm{F}_{\mathrm{fz}}$. Therefore, the surface feature shall slide longer to complete a wear process and results in an increase in aspect ratio of particles. In contrast, the accumulated layer of the component at the interface may reduce the actual penetration depth of the surface feature into PEEK. Thus, it would further shorten the lateral sliding distance, resulting in a reduction of aspect ratio of particles. Therefore, it is possible that IgG formed a thicker layer at the interface and reduced the penetration depth feature into PEEK. PEEK pin then decreased its lateral sliding distance, and was easily broken to form a granular shape of particles when concentration of IgG was increased. In contrast, immersing PEEK in HSA may increase the downward force, resulting in an increase of wear particles. However, the results suggested that DPPC may not change the penetration depth of the surface feature into PEEK, thus the aspect ratio remained the same when increasing the concentration of DPPC.

Both rod-like and granular shapes of carbon fiber reinforced-PEEK (CFR-PEEK) wear particles were identified in macrophages in human tissue retrieval studies, although both cases were not associated with joint arthroplasty failure $[27,28]$. In patients going through knee revision surgery, a small amount of synovial tissue was collected and varies sizes of CFR-PEEK particles formed conglomerates near to the vessel [29]. None of the biological responses were reported, and although PEEK wear particles were found in those patients, it is difficult to draw a conclusion of whether the size and the shape of PEEK wear particles influence biological response in humans. The testing procedure we applied here provided a rapid method for PEEK wear particle generation under different concentrations of HSA, IgG, and DPPC, thus providing a rapid way to compare morphology of PEEK wear particles. Furthermore, the wear process should be conducted by joint simulators in the future to imitate the clinical situation.

\subsection{Wear Rates Depend on the Concentration of $H S A, I g G$, and DPPC}

When PEEK pin was rubbed in HSA solution, increasing HSA concentration resulted in reducing wear rate (Figure 5 and Table 1). Although the reduction was more obvious when articulation of PEEK pins was in $0.5 \mathrm{mg} / \mathrm{mL}$ of HSA than in a higher concentration of HSA, the trend of mass wear generation was overall decreased, resulting in an increase of HSA. In contrast, increasing the concentration of both IgG and DPPC resulted in an increase of wear rate (Figure 5 and Table 1). 


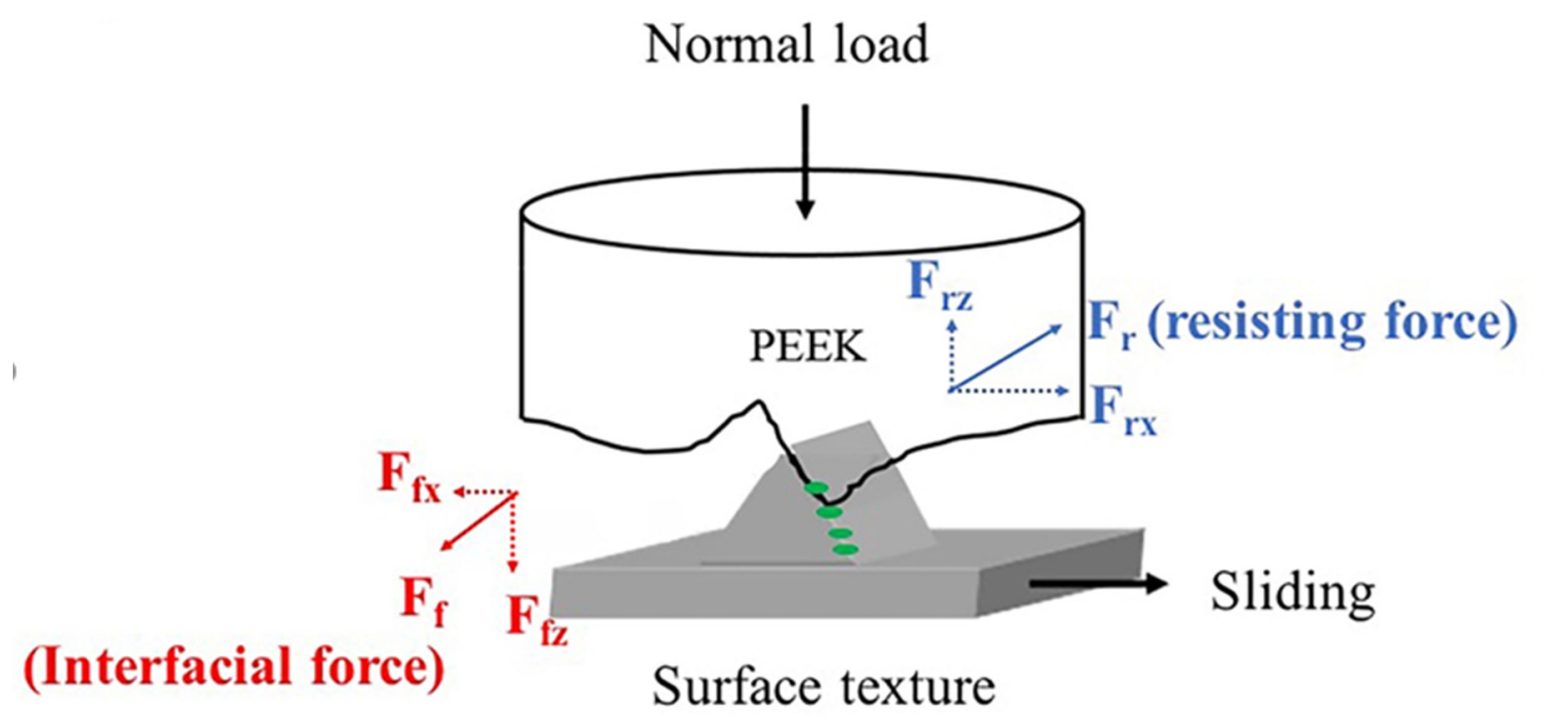

Figure 4. Mechanical analysis of the resisting force and interfacial friction for the surface feature sliding over PEEK process. $F_{r z}$ is upward direction of the resisting force; $F_{r x}$ is horizontal direction of the resisting force; $\mathrm{F}_{\mathrm{fz}}$ means downward direction of the interfacial friction; $\mathrm{F}_{\mathrm{fx}}$ is horizontal direction of the interfacial friction. Green circles represent the testing components such as HSA, IgG, or DPPC.

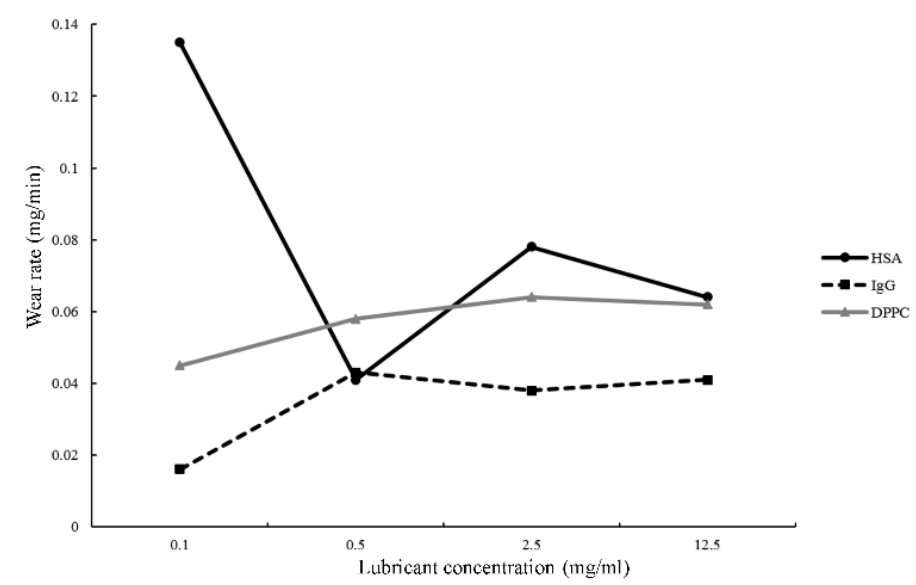

Figure 5. Wear rate of PEEK wear particles under the lubrication of HSA, IgG, or DPPC solution. Plots of aspect ratio and the wear rate in different concentrations of HSA, IgG or DPPC solution.

Our results demonstrated that the total wear rate was the lowest when PEEK was rubbing in IgG. The friction between artificial joints is boundary lubrication according to the Stribeck curve, and the lubricant will accumulate and form a thin layer on the surface to protect the joints [30]. It is possible that IgG forms a thicker layer on the surface of PEEK and the microfabricated edges resulting in reducing the penetration depth of the cutting edge into PEEK and reducing the numbers of wear particles. However, increasing the concentration of IgG still resulted in an increase of wear rate suggesting that lower concentration of IgG might be more suitable for protecting the surface of PEEK. In contrast, HSA may form a much thinner layer, thus higher concentration of HSA is needed to reduce the penetration of the cutting edge into PEEK. Therefore, a higher concentration of HSA caused a decrease of wear particles.

DPPC carries positively charged quaternary ammonium ion, and usually could adhere to negatively charged proteoglycans on the surface of cartilage [31]. The strong adhesion between DPPC and cartilage can reduce friction, and higher concentrations of DPPC can increase its lubricating ability [32]. In addition, DPPC can form DPPC bilayers and it has been shown that a reduction in wear 
between joint and cartilage can occur as long as DPPC bilayers are not separated from the surface [33]. However, PEEK is not cartilage thus there might not be strong adhesion between PEEK and DPPC. Increasing the concentration of DPPC may result in stronger adhesion among DPPC bilayers, and result in adhesive wear in our system, thus higher wear rate was obtained. Taken together, our results demonstrated that lower concentration of IgG and DPPC can be good lubricants in terms of reducing PEEK wear rate. In addition, the cost of manufacturing PEEK is high. Our results also provided additional information about the factors that could affect PEEK wear rate, thus the potential lubricants can be applied in reducing PEEK wear particles in biomedical systems for prolonging the lifetime of PEEK.

\section{Conclusions}

An accelerated wear testing procedure was established successfully to evaluate the lubrication effects of albumin, globulin, and phospholipids in this study. The morphologies of PEEK wear particles have been characterized, and the effects of different lubricants on the aspect ratio of wear particles have been investigated. The results for the wear rate can help us to discuss the lubricating ability of these three components. Although there is no conclusive trend for the wear rate obtained in this study, our scale-up testing system for generating PEEK wear particles has given us a rapid screening method for identifying the role of lubricants in the boundary lubrication of artificial joints. This testing method may be beneficial for further developing lubricating additives for total joint arthroplasties in the future.

Author Contributions: Conceptualization, H.-W.F.; Data curation, C.-Y.S. and H.-W.F.; Formal analysis, C.-Y.S. and S.-S.H.; Funding acquisition, H.-W.F.; Investigation, S.-S.H.; Methodology, S.-S.H. and H.-W.F.; Supervision, H.-W.F.; Validation, S.-S.H.; Writing-original draft, C.-Y.S.; Writing-review \& editing, H.-W.F.

Acknowledgments: This work was supported by the Ministry of Science and Technology (MOST), Taiwan under the grant number 105-2221-E-027-008-MY3 and 106-2622-8-027-001-TE4.

Conflicts of Interest: The authors declare no conflict of interest.

\section{References}

1. Beck, R.T.; Illingworth, K.D.; Saleh, K.J. Review of periprosthetic osteolysis in total joint arthroplasty: An emphasis on host factors and future directions. J. Orthop. Res. 2012, 30, 541-546. [CrossRef] [PubMed]

2. Harris, W.H. The problem is osteolysis. Clin. Orthop. Relat. Res. 1995, 311, 46-53.

3. Jiang, Y.; Jia, T.; Wooley, P.H.; Yang, S.Y. Current research in the pathogenesis of aseptic implant loosening associated with particulate wear debris. Acta Orthop. Belg. 2013, 79, 1-9. [PubMed]

4. Amstutz, H.C.; Campbell, P.; Kossovsky, N.; Clarke, I.C. Mechanism and clinical significance of wear debris-induced osteolysis. Clin. Orthop. Relat. Res. 1992, 276, 7-18. [CrossRef]

5. Chang, C.H.; Fang, H.W.; Ho, Y.C.; Huang, H.T. Chondrocyte acting as phagocyte to internalize polyethylene wear particles and leads to the elevations of osteoarthritis associated NO and PGE2. Biochem. Biophys. Res. Commun. 2008, 369, 884-888. [CrossRef] [PubMed]

6. Fang, H.W.; Yang, C.B.; Chang, C.H.; Huang, C.H.; Liu, H.L.; Fang, S.B. The potential role of phagocytic capacity in the osteolytic process induced by polyethylene wear particles. J. Int. Med. Res. 2006, 34, 655-664. [CrossRef] [PubMed]

7. Maloney, W.J.; Smith, R.L. Periprosthetic osteolysis in total hip arthroplasty: The role of particulate wear debris. Instr. Course Lect. 1996, 45, 171-182. [CrossRef] [PubMed]

8. Kurtz, S.M.; Muratoglu, O.K.; Evans, M.; Edidin, A.A. Advances in the processing, sterilization, and crosslinking of ultra-high molecular weight polyethylene for total joint arthroplasty. Biomaterials 1999, 20, 1659-1688. [CrossRef]

9. McKellop, H.; Shen, F.W.; Lu, B.; Campbell, P.; Salovey, R. Development of an extremely wear-resistant ultra high molecular weight polyethylene for total hip replacements. J. Orthop. Res. 1999, 17, 157-167. [CrossRef] [PubMed] 
10. Muratoglu, O.K.; Bragdon, C.R.; O'Connor, D.O.; Jasty, M.; Harris, W.H. A novel method of cross-linking ultra-high-molecular-weight polyethylene to improve wear, reduce oxidation, and retain mechanical properties. Recipient of the 1999 HAP Paul Award. J. Arthroplast. 2001, 16, 149-160. [CrossRef] [PubMed]

11. Kurtz, S.M.; Devine, J.N. PEEK biomaterials in trauma, orthopedic, and spinal implants. Biomaterials 2007, 28, 4845-4869. [CrossRef] [PubMed]

12. Wang, A.; Lin, R.; Stark, C.; Dumbleton, J.H. Suitability and limitations of carbon fiber reinforced PEEK composites as bearing surfaces for total joint replacements. Wear 1999, 225, 724-727. [CrossRef]

13. Green, T.R.; Fisher, J.; Matthews, J.B.; Stone, M.H.; Ingham, E. Effect of size and dose on bone resorption activity of macrophages by in vitro clinically relevant ultra high molecular weight polyethylene particles. J. Biomed. Mater. Res. 2000, 53, 490-497. [CrossRef]

14. Green, T.R.; Fisher, J.; Stone, M.; Wroblewski, B.M.; Ingham, E. Polyethylene particles of a 'critical size' are necessary for the induction of cytokines by macrophages in vitro. Biomaterials 1998, 19, 2297-2302. [CrossRef]

15. Liu, A.; Richards, L.; Bladen, C.L.; Ingham, E.; Fisher, J.; Tipper, J.L. The biological response to nanometre-sized polymer particles. Acta Biomater. 2015, 23, 38-51. [CrossRef] [PubMed]

16. Matthews, J.B.; Besong, A.A.; Green, T.R.; Stone, M.H.; Wroblewski, B.M.; Fisher, J.; Ingham, E. Evaluation of the response of primary human peripheral blood mononuclear phagocytes to challenge with in vitro generated clinically relevant UHMWPE particles of known size and dose. J. Biomed. Mater. Res. 2000, 52, 296-307. [CrossRef]

17. Matthews, J.B.; Green, T.R.; Stone, M.H.; Wroblewski, B.M.; Fisher, J.; Ingham, E. Comparison of the response of primary murine peritoneal macrophages and the U937 human histiocytic cell line to challenge with in vitro generated clinically relevant UHMWPE particles. Biomed. Mater. Eng. 1999, 10, 229-240.

18. Shanbhag, A.S.; Jacobs, J.J.; Black, J.; Galante, J.O.; Glant, T.T. Human monocyte response to particulate biomaterials generated in vivo and in vitro. J. Orthop. Res. 1995, 13, 792-801. [CrossRef] [PubMed]

19. Hallab, N.J.; McAllister, K.; Brady, M.; Jarman-Smith, M. Macrophage reactivity to different polymers demonstrates particle size- and material-specific reactivity: PEEK-OPTIMA((R)) particles versus UHMWPE particles in the submicron, micron, and 10 micron size ranges. J. Biomed. Mater. Res. B Appl. Biomater. 2012, 100, 480-492. [CrossRef] [PubMed]

20. Mizumoto, M.; Kato, K. Size distribution and number of wear particles generated by the abrasive sliding of a model asperity in the sem-tribosystem. Tribol. Ser. 1992, 21, 523-530.

21. Zmitrowics, A. Wear debris: A review of properties and constitutive models. J. Theor. Appl. Mech. 2005, 43, 3-35.

22. Su, C.Y.; Kuo, C.W.; Fang, H.W. Rapid Analyses of Polyetheretherketone Wear Characteristics by Accelerated Wear Testing with Microfabricated Surfaces for Artificial Joint Systems. Biomed. Res. Int. 2017, 2017, 5979564. [CrossRef] [PubMed]

23. Saikko, V.; Ahlroos, T. Phospholipids as boundary lubricants in wear tests of prosthetic joint materials. Wear 1997, 207, 86-91. [CrossRef]

24. Fang, H.W.; Wang, H.C.; Tsai, T.H.; Tsai, W.B.; Hou, S.Y.; Liu, H.L.; Lee, W.H.; Lu, Y.C.; Huang, C.H. Accelerated wear testing with a microfabricated surface to evaluate the lubrication ability of biomolecules on polyethylene. J. Appl. Polym. Sci. 2008, 108, 2428-2437. [CrossRef]

25. Evans, D.C. Polymer-fluid interaction in relation to wear. In Proceedings of the Third Leeds-Lyon Symposium on Tribology, the Wear of Non-Metallic Materials, Leeds, UK, 7-10 September 1978; pp. 47-55.

26. Lutton, M.D.; Stolarski, T.A. The effect of water lubrication on polymer wear under rolling contact condition. J. Appl. Polym. Sci. 1994, 54, 771-782. [CrossRef]

27. Latif, A.M.; Mehats, A.; Elcocks, M.; Rushton, N.; Field, R.E.; Jones, E. Pre-clinical studies to validate the MITCH PCR Cup: A flexible and anatomically shaped acetabular component with novel bearing characteristics. J. Mater. Sci. Mater. Med. 2008, 19, 1729-1736. [CrossRef] [PubMed]

28. Pace, N.; Marinelli, M.; Spurio, S. Technical and histologic analysis of a retrieved carbon fiber-reinforced poly-ether-ether-ketone composite alumina-bearing liner 28 months after implantation. J. Arthroplast. 2008, 23, 151-155. [CrossRef] [PubMed]

29. Paulus, A.C.; Hasselt, S.; Jansson, V.; Giurea, A.; Neuhaus, H.; Grupp, T.M.; Utzschneider, S. Histopathological Analysis of PEEK Wear Particle Effects on the Synovial Tissue of Patients. Biomed. Res. Int. 2016, 2016, 2198914. [CrossRef] [PubMed] 
30. Gleghorn, J.P.; Bonassar, L.J. Lubrication mode analysis of articular cartilage using Stribeck surfaces. J. Biomech. 2008, 41, 1910-1918. [CrossRef] [PubMed]

31. Hills, B.A.; Crawford, R.W. Normal and prosthetic synovial joints are lubricated by surface-active phospholipid: A hypothesis. J. Arthroplast. 2003, 18, 499-505. [CrossRef]

32. Forsey, R.W.; Fisher, J.; Thompson, J.; Stone, M.H.; Bell, C.; Ingham, E. The effect of hyaluronic acid and phospholipid based lubricants on friction within a human cartilage damage model. Biomaterials 2006, 27, 4581-4590. [CrossRef] [PubMed]

33. Hills, B.A.; Monds, M.K. Deficiency of lubricating surfactant lining the articular surfaces of replaced hips and knees. Br. J. Rheumatol. 1998, 37, 143-147. [CrossRef] [PubMed]

(C) 2018 by the authors. Licensee MDPI, Basel, Switzerland. This article is an open access article distributed under the terms and conditions of the Creative Commons Attribution (CC BY) license (http://creativecommons.org/licenses/by/4.0/). 